FINAL REPORT

CONTRACT NUMBER: DOE FG07-97-ER45670

\title{
INFLUENCE OF RADIATION AND MULTIVALENT CATION ADDITIONS ON PHASE SEPARATION AND CRYSTALLIZATION OF GLASS
}

\author{
Principal Investigator: \\ Michael C. Weinberg, MSE Dept., Bldg. \#12, University of Arizona, \\ Tucson, AZ 85721, telephone (520-621-6909), e-mail (mcw@u.arizona.edu) \\ Co-Principal Investigator: \\ Donald R. Uhlmann, MSE Dept., Bldg. \#12, University of Arizona, \\ Tucson, AZ 85721, telephone (520-322-2960), e-mail \\ (uhlmann@cobra.aml.arizona.edu) \\ Co-Principal Investigator: \\ Gary L. Smith, Dept. of Materials Science, Battelle PNNL, POB 999, Richland, WA \\ 99352, telephone (509-372-1957), e-mail (gary.l.smith@pnl.gov)
}

August 9, 2002

\begin{abstract}
This report presents results of: (1) measurement of valence state ratios of iron in glass, and (2) a study of the effect of iron redox ratio on phase separation behavior in a glass. The redox ratio of iron in two sodium silicate (NS) glasses has been determined using a colorimetric method, Mossbauer analysis, and optical absorption. The experimental procedures were described in a previous report. We found that these three methods gave excellent agreement for the values of the $\mathrm{Fe}^{++} / \mathrm{Fe}^{+++}$(redox ratio) in the glasses. Also, using the results of the colorimetric analysis we were able to find the extinction coefficients for the $18.56 \%$ NS and the $13 \%$ NS glasses.

We have utilized the optical absorption data that was taken for purposes of determining redox ratios to provide glass structural information. In particular, it has been suggested that the band centered near $14,500 \mathrm{~cm}^{-1}$ is indicative of $\mathrm{Fe}^{2+}-\mathrm{O}^{2-}-\mathrm{Fe}^{3+}$ formation. In addition, the relative band intensities at $10,000 \mathrm{~cm}^{-1}$ and $4,800 \mathrm{~cm}^{-1}$ could give us information as to the environment around the $\mathrm{Fe}^{2+}$ responsible for the $4,800 \mathrm{~cm}^{-1}$ band. The Mossbauer data will provide supporting structural information. For example, the relative number of clustered and free ferric ions can be computed from the ratio of areas under the doublet and sextet in the liquid He spectra. Also, the change in shift parameter with redox ratio will provide an indication of whether there is an increase or decrease in tetrahedral site symmetry about both ferrous and ferric ions. Finally, the
\end{abstract}


quadrupole splitting parameter provides information regarding the site symmetries about the $\mathrm{Fe}^{++}$and $\mathrm{Fe}^{+++}$. Currently, we are analyzing the spectral data for these purposes. The Mossbauer work was done in conjunction with colleagues at PNNL, and a manuscript is currently in preparation.

The effect of oxidation state of iron on the phase separation of $x \mathrm{Na}_{2} \mathrm{O} \cdot(100-x) \mathrm{SiO}_{2}$ glasses, $x=18.56$ and 13 , containing 0.5 mole $\%$ iron oxide was studied. The oxidation state of iron in the glasses was varied by changing the melting conditions such as melting temperature and melting atmosphere. The oxidation states of the iron ion were determined by the colorimetric method and by the UV-VIS NIR spectrophotometric method, and a comparison was made between the results obtained using these two techniques. Immiscibility temperatures of the glasses were determined by opalescence and clearing methods. The immiscibility temperature of the sodium silicate binary glasses decreased approximately $25^{\circ} \mathrm{C}$ with the addition of 0.5 mole $\% \mathrm{Fe}_{2} \mathrm{O}_{3}$. The immiscibility temperature of the doped glasses increased slightly with increasing concentration of $\mathrm{Fe}^{2+}$ ion in the glass.

The liquidus temperature of the $18.56 \mathrm{NS}_{2}$ glass was determined using an X-ray diffraction technique. Approximately 3 grams of glass powder were heated for 4 hours in the temperature region near the liquidus temperature. XRD patterns were obtained from the samples to determine if any crystalline material was present. The heat-treatment temperatures were incremented in $2{ }^{\circ} \mathrm{C}$ intervals, and the liquidus temperature was taken as the minimum heat-treatment temperature where the crystalline XRD peaks disappeared in the XRD pattern. From this analysis is was determined that the liquidus temperature decreased about $26{ }^{\circ} \mathrm{C}$ by the addition of 0.5 mole $\% \mathrm{Fe}_{2} \mathrm{O}_{3}$.

The prediction of immiscibility tendency upon the addition of a minor amount of third component was made using models proposed by Tomozawa and Obara and Nakagawa and Izumitani. Tomozawa and Obara's model showed good agreement with the measured immiscibility values. 


\section{Report}

\section{RESEARCH OBJECTIVES}

The major objectives of the proposed investigation were as follows:

(1) To investigate the influence of multivalent cations on the thermodynamics and kinetics of phase separation and crystallization in simple model glasses. (2) To study the influence of alpha and beta particles, heavy ion bombardment and gamma irradiation on phase separation and crystallization in simple model glasses. (3) To examine the structural changes produced by radiation just prior to the onset of phase separation and/or crystallization. (4) To develop models to explain the observed effects of multivalent cations and radiation on phase separation and crystallization. (5) To utilize the results of these experimental and modeling studies to provide guidelines for the allowed range of composition choices and processing conditions in order to avoid the formation of unwanted phases in nuclear waste disposal glasses.

\section{RESEARCH PROGRESS -- Effect of oxidation state of iron on phase separation in sodium silicate glasses}

\section{Introduction}

It has been recognized that liquid-liquid immiscibility and crystallization processes have significant potential to alter the storage behavior ${ }^{1}$ in glasses used for nuclear waste disposal. In order to mitigate the chance for deleterious phase separation during storage of nuclear-waste-loaded glasses it is necessary to examine the influence of multivalent cations on the thermodynamics and kinetics of the phase transformation process. In general, transition metal ions can exist in multivalent states depending upon the base glass composition, temperature of melting, duration of heat treatment, and partial pressure of oxygen above the glass melt. ${ }^{2}$ A number of multivalent elements can be present in high level nuclear waste that is to be immobilized within a glass matrix. Among such multivalent elements, prime attention should be paid to iron since high level radioactive wastes inevitably contain iron oxide. Under normal conditions, iron can be present in silicate glasses only as $\mathrm{Fe}^{2+}$ and $\mathrm{Fe}^{3+}$.

The oxidation state of a glass is expected to influence the immiscibility tendency since $\mathrm{Fe}^{2+}$ and $\mathrm{Fe}^{3+}$ have different ionic field strengths and different coordination numbers in the glass. In this study, the effect of the oxidation state of iron on phase separation was investigated using two different compositions of sodium silicate binary glasses. 


\section{Experimental}

\section{(1) Glass preparation}

Sodium silicate base glasses were prepared with the composition of $x \mathrm{Na}_{2} \mathrm{O} \cdot(100-$ $x) \mathrm{SiO}_{2}, x=13$ and 18.56 . The 13 mole \% glass was melted using reagent grade $\mathrm{Na}_{2} \mathrm{CO}_{3}$ and silica powder $\left(\mathrm{SiO}_{2}\right)$ at $1600{ }^{\circ} \mathrm{C}$ for 8 hours in a platinum crucible in an electric furnace. The glass melt was poured on a brass plate and cooled to room temperature. Homogenization of glass was achieved by crushing and re-melting two times. The 18.56 mole \% glass had been previously prepared at Owens-Illinois. ${ }^{3}$ Sodium silicate glasses doped with 0.5 mole $\% \mathrm{Fe}_{2} \mathrm{O}_{3}$ were prepared in 150 gram batches by melting the crushed base glass powder and reagent grade $\mathrm{Fe}_{2} \mathrm{O}_{3}$. It should be noted that both base composition glasses used in this study were from the same initial melt, so no variation in base glass composition occurred for the different melts.

Most batches of the iron containing glasses were melted at $1300-1600{ }^{\circ} \mathrm{C}$ in a platinum crucible for 1.5-8 hrs then poured into a brass mold of approximately 4 by 4 by $2 \mathrm{~cm}$, then annealed at $500{ }^{\circ} \mathrm{C}$ for $2 \mathrm{hrs}$ and furnace cooled. In order to vary the oxidation state of iron in the glass, different melting temperatures, melting times and atmosphere were used. In order to obtain highly reduced glasses, a $\mathrm{CO} / \mathrm{CO}_{2}$ gas mixture was bubbled into the glass melt while the glass was molten. The gas mixture was introduced into the melt through a platinum tube. Before the glass was removed from the furnace, the tube was withdrawn from the melt and gas was allowed to flow over the surface of the melt for a period of 30 minutes. This procedure allowed bubbles to be removed from the melt while still maintaining the reduced atmosphere over the glass. The melting conditions used in this study are shown in Table I.

\section{(2) Measurement of $\mathrm{Fe}^{2+} /(\mathrm{Fe}$ ratio}

To measure the ratio of $\mathrm{Fe}^{2+} /(\mathrm{Fe}$ in the glasses two different techniques, colorimetric $^{4-6}$ and UV-VIS NIR spectrophotometric methods, ${ }^{7,8}$ were used. In the colorimetric method, ferrous ions react with 1,10-phenanthroline and forms the orangered complex $\left(\left(\mathrm{C}_{12} \mathrm{H}_{8} \mathrm{~N}_{2}\right) 3 \mathrm{Fe}^{2+}\right)$ in solution over a $\mathrm{pH}$ range of 2-9. Optical absorbance of this complex at $510 \mathrm{~nm}$ follows Lambert-Beer's law. Therefore, optical absorbance of the solution containing that complex can be converted to a concentration of $\mathrm{Fe}^{2+}$ in the solution. Calibration curves for converting measured absorbance to concentration of $\mathrm{Fe}^{2+}$ were established at $510 \mathrm{~nm}$ using an atomic absorption iron standard solution.

For the analysis of ferrous ion concentration, glass samples were ground to a fine powder using an alumina mortar and pestle. About 20-30 mg of the glass powder sample was weighed into a $100 \mathrm{ml}$ plastic beaker. An indicating solution of $25 \mathrm{ml}$ of $4 \%$ boric acid, $7 \mathrm{ml}$ of $10 \%$ potassium hydrogen phthalate, $6 \mathrm{ml}$ of $0.25 \% 1$,10-phenanthroline solution, and $2 \mathrm{ml}$ of concentrated ammonium hydroxide was prepared in a second 100 $\mathrm{ml}$ plastic beaker. The glass powder was then digested by the addition of $0.5 \mathrm{ml}$ of concentrated $\mathrm{H}_{2} \mathrm{SO}_{4}$ and $1.5 \mathrm{ml}$ of concentrated $\mathrm{HF}$ into the sample beaker. Immediately after dissolution of the glass (within 15 seconds of the addition of the acids to the glass powder), the indicating solution described above was added and the $\mathrm{pH}$ of the mixed solution was adjusted to 3.3-3.5 using diluted ammonium hydroxide and/or diluted $\mathrm{H}_{2} \mathrm{SO}_{4}$. This solution was transferred to $100 \mathrm{ml}$ volumetric flask and diluted to $100 \mathrm{ml}$ by adding iron free deionized water. Visible spectrophotometric absorbance measurement 
of the sample solution was made with a Milton Roy Spectronic 2101 digital UV-VIS Spectrophotometer using a matched polystyrene cell.

For the analysis of total iron, $20 \mathrm{ml}$ of the above sample solution was transferred to $100 \mathrm{ml}$ plastic bottle and hydroquinone $(25$ ( $5 \mathrm{mg}$ ) was added to the solution to reduce all the ferric ions to ferrous ions. The absorbance of this solution was measured after full color development of the orange-red complex. The measured absorbances were converted to concentration of $\mathrm{Fe}^{2+}$ and total iron present in the solution. This allowed the ratio of $\mathrm{Fe}^{2+} /(\mathrm{Fe}$ to be calculated from the measured absorbance values.

UV-VIS NIR spectroscopy was also used to determine the $\mathrm{Fe}^{2+} /(\mathrm{Fe}$ ratio in these glasses. This method provides a direct evaluation of the $\mathrm{Fe}^{2+}$ content in glass without having to carry out chemical dissolution. However, knowledge of the extinction coefficient of the $\mathrm{Fe}^{2+}$ ion in the given glass composition is required. The ferrous ion in a glass has a maximum absorption peak around $1100 \mathrm{~nm}$ in the optical spectra. The position and intensity of this peak varies with the base glass composition. There is a linear relationship between the optical absorbance at this peak position and the $\mathrm{Fe}^{2+}$ ion concentration for a glass of constant composition. Therefore, the amount of ferrous iron in the glass can be found by the spectrophotometric method. Each of the bulk glasses, annealed at $500{ }^{\circ} \mathrm{C}$ for 2 hours, was cut into pieces of dimensions 10 ( $10 \mathrm{~mm}$ with four different thicknesses $(1.5,2.0,2.5$ and $3.0 \mathrm{~mm})$ using a low speed diamond saw. After cutting, all glass samples were ground using flat alumina grinding media and then polished using $1\left(\mathrm{~m} \mathrm{CeO}_{2}\right.$ to achieve uniform thickness and parallel and polished surfaces.

Spectrophotometric absorbances of glasses were measured by a Varian 500 Scan Spectrophotometer with a double beam mode. Since the extinction coefficient for our glasses were not known, we calculated the extinction coefficient using the Lambert-Beer equation. The Lambert-Beer equation is given by $\mathrm{A}=$ (ct, where $\mathrm{A}=$ absorbance (dimensionless), ( = extinction coefficient $\left(\mathrm{mm}^{-1}\right), \mathrm{c}=$ concentration of ferrous ion $\left(\mathrm{Fe}^{2+} /(\mathrm{Fe})\right.$, and $t=$ sample thickness $(\mathrm{mm})$. A plot of absorbance near $1100 \mathrm{~nm}$ versus thickness gives a linear relation, and the slope of this plot is (c. To find the extinction coefficient, the concentration of ferrous ion $\left(\mathrm{Fe}^{2+} /(\mathrm{Fe})\right.$ obtained from the colorimetric method was used. Then, the ratio of $\mathrm{Fe}^{2+} /(\mathrm{Fe}$ for each of the glasses was determined using the calculated extinction coefficient and the slope of the absorbance vs. thickness plot.

\section{(3) Determination of immiscibility temperature}

The immiscibility temperatures of glasses were determined by both opalescence and clearing methods. ${ }^{9,10}$ In the opalescence method, glass samples of approximately $10(10(5 \mathrm{~mm}$ were held at temperatures near the expected binodal temperature for various times depending upon the glass composition and heat-treatment temperature. The heattreated samples were then evaluated to determine if phase separation had occurred.

In the clearing method one determines the minimum heat-treatment temperature at which a previously phase separated glass clears. The detection of opalescence and clearing by the naked eye can be aided by the use of a concentrated beam of light, such as a laser beam, or by placing the sample in an index matching solution and viewing against a black background. If the samples showed any evidence of surface 
crystallization, then the crystalline material was removed before seeking signs of the presence of phase separation. The accuracy of these techniques is determined by the temperature interval between the heat-treatment temperatures and the number of samples used.

\section{(4) Liquidus temperature measurement}

X-ray diffraction ${ }^{11}$ was used to determine liquidus temperatures of the $18.56 \mathrm{Na}_{2} \mathrm{O} \cdot 81.44 \mathrm{SiO}_{2}$ base glass and the 0.5 mole $\% \mathrm{Fe}_{2} \mathrm{O}_{3}$ doped glass. To measure liquidus temperature approximately 3 grams of glass powder was heated in the temperature range of $1130-1180{ }^{\circ} \mathrm{C}$ for $4 \mathrm{hrs}$. X-ray diffraction patterns were obtained after each heat-treatment to determine if crystalline material was present. In order to find a precise value of the liquidus temperature successive heat-treatment experiments, with 2 ${ }^{\circ} \mathrm{C}$ intervals, were performed at the temperatures close to the anticipated liquidus temperature as determined from the initial measurements. The liquidus temperature was taken as the minimum heat treatment temperature where all of the crystalline peaks disappeared in the XRD pattern. XRD measurements were performed using a step scan with a 0.02 degree step with an integration time of 2 seconds at each step.

\section{Results and Discussion}

\section{(1) Oxidation state of iron by the colorimetric method}

The results of measurements of oxidation states by the colorimetric method are shown in Table II. As one expects from the redox equilibrium of iron, the concentration of ferrous ion in the glass increases with increasing melting temperature and with increasing the ratio of $\mathrm{CO} / \mathrm{CO}_{2}$ bubbling gases for a given melting temperature. Column 2 of this table shows the measured percentage of iron in the $\mathrm{Fe}^{2+}$ state. The error in these values, shown in the third column, was computed from data obtained by repeated evaluations of the same glass. The fourth column contains the measured total amount of iron. The last column gives the anticipated amount of iron in the glass if one assumes that there is no batch loss due to volatility. One observes that there is generally good agreement between the measured and expected values of the total iron content.

The possible sources of errors for oxidation ratio of iron by this method are the oxidation of ferrous ion during decomposition of glass, and the formation of precipitate after mixing the indicating solution into the decomposed glass solution. The potential for the oxidation of the ferrous iron ion was significantly reduced by using very finely ground glass powder to reduce the time for complete dissolution of the glass to less than 15 seconds, and by introducing the indicating solution immediately after dissolution. Precipitation could be avoided by adjusting the $\mathrm{pH}$ of the solution quickly after introducing the indicating solution into the digested glass solution. 


\section{(2) UV-VIS NIR spectroscopic method}

The UV-VIS NIR absorbance spectra of the 13NS-series glasses are shown Figure 1. One can clearly see that the absorbance near $1100 \mathrm{~nm}$, due to the $\mathrm{Fe}^{2+}$ ion, increases with increasing $\mathrm{Fe}^{2+}$ ion concentration in the glass. The results of linear regression analysis of absorbance near $1100 \mathrm{~nm}$ versus thickness for each of the 13NS-series and 18NS-series glasses are shown in Figures 2 and 3. All linear regression lines showed an excellent fit to the data, with correlation coefficients close to 1 . From these plots we confirmed that the absorbance of the $\mathrm{Fe}^{2+}$ ion in theses glasses followed Lambert-Beer's law. The slopes of the lines in the figures gives the product of the $\mathrm{Fe}^{2+}$ concentration and the extinction coefficient. We used the results of the $\mathrm{Fe}^{2+} /(\mathrm{Fe}$ concentrations determined by the colorimetric method and the slope of the line from the figures to determine an extinction coefficient for each individual glass sample (Table III). An average extinction coefficient for each base glass composition with 0.5 mole $\% \mathrm{Fe}_{2} \mathrm{O}_{3}$ addition was then calculated from the individual results. Using the calculated average extinction coefficients, concentrations of $\mathrm{Fe}^{2+} /(\mathrm{Fe}$ for each of the glasses were then determined from the experimental absorbance measurements. These results are shown in Table IV.

In the UV-VIS NIR spectrophotometric method, the main causes of error are small bubbles in the specimen, lack of uniformity of thickness, and poor specimen homogeneity, all of which can affect the absorbance, and hence the calculation of the extinction coefficient. In order to enhance the accuracy of measurement, care is required during the specimen preparation processes.

\section{(3) Comparison of colorimetric and UV-VIS NIR spectroscopic methods}

The colorimetric method is relatively accurate and can be used to analyze concentrations of $\mathrm{Fe}^{2+}, \mathrm{Fe}^{3+}$ and total $\mathrm{Fe}$ in one glass digestion, but it is tedious and time consuming and cannot be applied in an in-line analysis. The spectrophotometric method is very simple and quick, but one must depend on wet chemical methods to obtain the extinction coefficient. However, once the glass is well characterized by a wet chemical method, one can apply the spectrophotometric method to in-line analysis of the oxidation state of iron in a glass factory for rapid determination of the oxidation state.

The results of the two methods in the present study can be compared in a couple of ways. First, in Fig. 4(a, b) we compare the results for the 18NS and 13NS glasses, respectively, by plotting the \% ferrous ion found by the spectrophotometric method versus the $\%$ ferrous ion found by the colorimetric method. One observes excellent agreement between the methods for all oxidation state ratios, save the most reduced glass. Although the reason for the discrepancy in this composition is not known, it could be related to the quality of this glass and its somewhat inhomogeneous nature. The former comparison procedure is somewhat tainted in that the results of the colorimetric experiments were used to obtain the extinction coefficient employed in the spectrophotometric technique. Hence, we chose to use a second method of comparison using concentration ratios so that prior knowledge of the extinction coefficient is not required. If one assumes that the extinction coefficient is independent of concentration (which is an excellent assumption in the low concentration regime), then the ratio of slopes in Figures 2 and 3 should give the concentration ratios. These ratios are shown in Table V in the columns labeled "Slope Ratio". The concentration ratios found from the 
colorimetric technique are given in the columns called "Concentration Ratio". Once again one observes excellent agreement between the results of the two methods, with the exception of glass $13 \mathrm{NS}-50 / 50$.

The molar extinction coefficients determined in this study have been compared to published values of molar extinction coefficients found in the literature for glasses of similar composition. These extinction coefficients are shown in Table VI. One can see that the extinction coefficients determined in the present study are similar to those found in the literature.

\section{(4) Immiscibility temperatures of glasses}

Binodal (i.e. immiscibility) temperatures were found by using both the opalescence (clouding) and clearing methods. In order to evaluate the accuracy of these two techniques, the binodal temperature of the $18 \mathrm{NS}$ base glass (not doped with $\mathrm{Fe}$ ) was determined. When this glass was heated for 8 hours anywhere in the temperature range $600{ }^{\circ} \mathrm{C}-630{ }^{\circ} \mathrm{C}$, phase separation occurred. However, long time heat treatments (up to 48 hours) of the glass above this temperature did not produce phase separation. Clearing of these phase separated glasses occurred near $660{ }^{\circ} \mathrm{C}$. Since the immiscibility temperature determined by opalescent and clearing should be fairly close, we felt that the opalescent technique was in error. We surmised that the source of the difficulty was the lack of ability of the glass to nucleate in the higher temperature regime. In order to overcome this problem we used two-stage heat treatments. The glasses were given a 24 hour heat treatment, the $18 \mathrm{NS}$ glass at $530{ }^{\circ} \mathrm{C}$ and the $13 \mathrm{NS}$ glass at $580{ }^{\circ} \mathrm{C}$, prior to the heat treatment at the clouding temperature. Using two-stage heating, the differences in binodal temperatures found by clearing and clouding methods were reduced to $5{ }^{\circ} \mathrm{C}$. However, comparison of the results of these methods with FE-SEM (see Figs. 5, 6) indicated that the clearing technique was more accurate. Also, due to the simplicity of the latter method, it was decided to rely solely upon this technique for subsequent investigations. All immiscibility temperatures reported here were obtained from clearing experiments. Oxidation ratio measurements were made in several cases upon completion of immiscibility determinations in order to ensure that the iron oxidation ratio did not change as a result of the heat treatment.

The results of the immiscibility temperature for the 18NS and 13NS series glasses as a function of oxidation state of iron are shown in Figure 7 and Table VII. One can observe from the figure that the addition of 0.5 mole $\% \mathrm{Fe}_{2} \mathrm{O}_{3}$ to both the $13 \mathrm{NS}$ and $18 \mathrm{NS}$ base glass causes a decrease in the binodal temperature. This decrease is relatively constant for all oxidation states, on average approximately $25{ }^{\circ} \mathrm{C}$, though there is a slight increase in binodal temperature as the $\mathrm{Fe}^{2+}$ concentration increases.

The effects of addition of third components on the immiscibility tendency of binary glass systems have been studied by Nakagawa and Izumitani ${ }^{16}$ and Tomozawa and Obara. ${ }^{17}$ Nakagawa and Izumitani ${ }^{16}$ suggested a simple criterion to predict the tendency of immiscibility of binary glass with addition of a third component by applying Prigogine's theory ${ }^{18}$ to ternary glasses.

Prigogine's theory ${ }^{18}$ is based on the use of a regular solution model, and the underlying idea of the method is to ascertain if the addition of a third component will 
lower or raise the critical temperature, $T_{c}$, of the binary mixture. The variation of $T_{c}$ with concentration of third component is expressible in terms of three parameters, $\alpha_{\mathrm{AB}}, \alpha_{\mathrm{AC}}$, $\alpha_{\mathrm{BC}}$, where $\alpha_{\mathrm{IJ}}=\mathrm{Z}\left\{\mathrm{W}_{\mathrm{IJ}}-1 / 2\left[\mathrm{~W}_{\mathrm{II}}+\mathrm{W}_{\mathrm{JJ}}\right]\right\}, \mathrm{Z}$ is the coordination number and $\mathrm{W}$ is a bond energy. If $C$ refers to the minor component and $\alpha_{A B}>\left(\alpha_{A C}-\alpha_{B C}(\right.$, then the tendency towards phase separation decreases. However, if the latter inequality is reversed, then the tendency towards immiscibility increases. We have employed this model assuming that all the iron is in the $\mathrm{Fe}^{2+}$ state or all is in the $\mathrm{Fe}^{3+}$ state. In both cases the model predicts a decrease in immiscibility tendency (as observed).

Tomozawa and Obara ${ }^{17}$ proposed a simple method for estimating the effect of a minor third component on the metastable immiscibility temperature of binary glasses. According to their model, the change in immiscibility temperature caused by the addition of a third component is approximately equal to the change in the liquidus temperature when the entropy change is small.

Although the decrease of immiscibility temperature with addition of $\mathrm{Fe}_{2} \mathrm{O}_{3}$ is easy to rationalize, the variation of binodal temperature with redox state is much more puzzling. The reason for the insensitivity of the immiscibility temperature to the iron oxidation state ratio (especially in the $18 \mathrm{NS}$ composition) is not clear. In the $13 \mathrm{NS}$ composition there is a more apparent, but small, rise in immiscibility content as the $\mathrm{Fe}^{2+}$ concentration increases. This result is difficult to understand since on the basis of ionic field strength arguments one would expect a decrease in binodal temperature.

Tomozawa et. al. ${ }^{19}$ have examined the influence of iron oxidation state upon immiscibility in a borosilicate glass. They observed that as the $\mathrm{Fe}^{2+}$ concentration increases the binodal temperature first decreases and then increases. They explained the rise in immiscibility temperature in terms of $\mathrm{Fe}^{2+}-\mathrm{Fe}^{3+}$ and $\mathrm{Fe}^{3+}-\mathrm{Fe}^{3+}$ clustering. It is possible that similar effects come into play for our system, but structural studies would be needed to confirm this hypothesis.

In order to apply Tomozawa and Obara's ${ }^{17}$ ideas to the present system we performed liquidus measurements on the $18 \mathrm{NS}$ glasses. The liquidus determinations were made using XRD intensities as function of temperature. Figure 8 shows the diffraction patterns of the $18.56 \mathrm{Na}_{2} \mathrm{O} \cdot 81.44 \mathrm{SiO}_{2}$ base glass and the glass doped with 0.5 mole $\% \mathrm{Fe}_{2} \mathrm{O}_{3}$, both below and at the liquidus temperature. Tridymite was the predominant crystalline phase for both glasses when the ground glasses were heattreated. The three most intense diffraction peaks for tridymite occurs near $2\left(\right.$ of $20.6^{\circ}$, $21.7^{\circ}$, and $23.3^{\circ}$. The liquidus temperature of the $18.56 \mathrm{Na}_{2} \mathrm{O} \cdot 81.44 \mathrm{SiO}_{2}$ base glass determined by this procedure was $1184\left(2{ }^{\circ} \mathrm{C}\right.$. This result shows good agreement with the established $\mathrm{Na}_{2} \mathrm{O}-\mathrm{SiO}_{2}$ phase-diagram information for this composition. ${ }^{20}$ The liquidus temperature of this glass doped with 0.5 mole $\% \mathrm{Fe}_{2} \mathrm{O}_{3}$ was found to be 1158 ( 2 ${ }^{\circ} \mathrm{C}$. The addition of 0.5 mole $\% \mathrm{Fe}_{2} \mathrm{O}_{3}$ to the $18 \mathrm{NS}$ base glass resulted in a decrease in liquidus temperature of about $26{ }^{\circ} \mathrm{C}$. As the change in immiscibility temperature was on average about $25{ }^{\circ} \mathrm{C}$, our results are in good accord with the Tomozawa and Obara model. 


\section{Conclusions}

The oxidation states of iron in sodium silicate glasses were determined by means of two different methods, colorimetric and spectrophotometric, and the results given by these two methods were in good agreement.

The liquidus temperature of $18.56 \mathrm{Na}_{2} \mathrm{O} \cdot 81.44 \mathrm{SiO}_{2}$ glass decreased about $26{ }^{\circ} \mathrm{C}$ by the addition of 0.5 mole $\% \mathrm{Fe}_{2} \mathrm{O}_{3}$. The immiscibility temperatures of $18 \mathrm{NS}$-series and 13NS-series glasses decreased about $25^{\circ} \mathrm{C}$ by adding 0.5 mole $\% \mathrm{Fe}_{2} \mathrm{O}_{3}$, and were almost independent of oxidation state of iron in the glass. The decrease in binodal temperatures were found to be in good agreement with a model proposed by Tomozawa and Obara. 


\section{References}

1. J.F. Sproull, S.L. Marra and C.M. Jantzen, "High Level Radioactive Waste Glass Production and Product Description"; pp. 15-25 in Scientific Basis for Nuclear Waste Management XVII, Proceedings of the Materials Research Society Symposium Volume 333 (Boston, MA, November 1993). Edited by A. Barkatt and R.A. Van Konynenburg. Materials Research Society, Pittsburgh, 1994.

2. A. Paul, "Oxidation-Reduction Equilibrium in Glass," J. Non-Cryst. Solids, $123354-$ 362 (1990).

3. M.C. Weinberg and G.F. Neilson, "Phase Separation Behavior of a Metal-Organic Derived Sodium Silicate Glass," J. Mater. Sci., 13 1206-1212 (1978).

4. ASTM Standard C169-92, "Standard Test Methods for Chemical Analysis of SodaLime and Borosilicate Glass" Annual Book of ASTM Standards, Vol 15.02, pp. 4264 (1999).

5. D.R. Jones IV, W.C. Jansheski, and D.S. Goldman, "Spectrophotometric Determination of Reduced and Total Iron in Glass with 1,10-Phenanthroline," J. Am. Ceram. Soc., 53 [6] 923-924 (1981).

6. Technical Committee 2 of the International Commission on Glass, "Determination of Ferrous Iron and Total Iron in Glass by a Colorimetric Method," Glass Technol., 40 [1] 24-28 (1999).

7. C.R. Bamford, Colour Generation and Control in Glasses, Elsevier, Amsterdam, 1977 Vol. 2

8. J.P. Traverse, T. Toganics and C. Ades, "Spectrophotometric Analysis of Ferrous, Ferric and Total Iron Content in Soda-Lime-Silica Glass" Glastech. Ber., 65 201-206 (1992).

9. W. Haller, D.H. Blackburn, and J.H. Simmons, "Miscibility Gaps in Alkali-Silicate Binaries - Data and Thermodynamic Interpretation," J. Am. Ceram Soc., 57 [3] 120$126(1974)$

10. O.V. Mazurin and E.A. Porai-Koshits, Phase Separation in Glass, North-Holland, Amsterdam, 1984.

11. M.C. Weinberg and G.F. Neilson, "Elevation of Liquidus Temperature in a GelDerived $\mathrm{Na}_{2} \mathrm{O}-\mathrm{SiO}_{2}$ Glass," J. Am. Ceram. Soc., 66 [2] 132-134 (1983).

12. F.N. Steele and R.W. Douglas, Phys. Chem. Glasses, 6 [6] 246 (1965).

13. A. Paul, "A Rapid Method for the Estimation of Trivalent Arsenic in Glass," Glass Technol., 6 [1] 22-25 (1965). 
14. M.S. Zaman and A. Paul, "A Rapid Method for the Estimation of Redox Ions in IronSulphur Amber Glasses," Glass Technol., 10 [4] 93-98 (1969).

15. F.R. Bacon and C.J. Billian, "Color and Spectral Transmittance of Amber Bottle Glass,” J. Am. Ceram. Soc., 37 [2] 60-66 (1954).

16. K. Nakagawa and T. Izumitani, "Effect of a Third Component upon the Immiscibility of Binary Glass," Phys. Chem. Glasses, 13 [3] 85-90 (1972).

17. M. Tomozawa and R.A Obara, "Effect of Minor Third Components on Metastable Immiscibility Boundaries of Binary Glasses," J. Am. Ceram. Soc., 56 [7] 378-381 (1973).

18. I. Prigogine and R. Defay, Chemical Thermodynamics, Translated by D.H. Everett, Longmans Green, London, (1954).

19. M. Tomozawa, G.M. Singer, R.K. MacCrone, and J.T. Warden, "Mixed Valence Effect in Phase Separation of Sodium Borosilicate Glasses," J. Non-Cryst. Solids, 49 165-171 (1982).

20. F.C. Kracek, “The System Sodium Oxide-Silica,” J. Am. Chem. Soc., 61 2863-2877 (1930). 
Table I. Composition and melting conditions of glasses

\begin{tabular}{|c|c|c|}
\hline Glass & $\begin{array}{l}\text { Composition } \\
\text { (Mole \%) }\end{array}$ & $\begin{array}{c}\text { Melting condition } \\
\text { Temp. }\left({ }^{\circ} \mathrm{C}\right) / \text { Time }(\text { hr }) / \text { Atmosphere }\end{array}$ \\
\hline $18 \mathrm{NS}$ & $18.56 \mathrm{Na}_{2} \mathrm{O} \cdot 81.44 \mathrm{SiO}_{2}$ & 1565/74/Air \\
\hline $18 \mathrm{NS}-1300$ & $\begin{array}{c}18.56 \mathrm{Na}_{2} \mathrm{O} \cdot 81.44 \mathrm{SiO}_{2} \\
+0.5 \mathrm{~mole} \% \mathrm{Fe}_{2} \mathrm{O}_{3}\end{array}$ & 1300/8/Air \\
\hline $18 \mathrm{NS}-1400$ & & 1400/8/Air \\
\hline $18 \mathrm{NS}-1500$ & & 1500/8/Air \\
\hline $18 \mathrm{NS}-1600$ & & 1600/8/Air \\
\hline $18 \mathrm{NS}-12 / 88$ & & $1500 / 1.5 /$ Gas bubbling $\left(\mathrm{CO} / \mathrm{CO}_{2}=12 / 88\right)$ \\
\hline $18 \mathrm{NS}-24 / 76$ & & $1500 / 1.5 /$ Gas bubbling $\left(\mathrm{CO} / \mathrm{CO}_{2}=24 / 76\right)$ \\
\hline $18 \mathrm{NS}-36 / 64$ & & $1500 / 1.5 /$ Gas bubbling $\left(\mathrm{CO} / \mathrm{CO}_{2}=36 / 64\right)$ \\
\hline $18 \mathrm{NS}-50 / 50$ & & $1500 / 1.5 /$ Gas bubbling $\left(\mathrm{CO} / \mathrm{CO}_{2}=50 / 50\right)$ \\
\hline $13 \mathrm{NS}$ & $13 \mathrm{Na}_{2} \mathrm{O} \cdot 87 \mathrm{SiO}_{2}$ & 1600/20/Air \\
\hline $13 \mathrm{NS}-1400$ & $\begin{aligned} & 13 \mathrm{Na}_{2} \mathrm{O} \cdot 87 \mathrm{SiO}_{2} \\
+ & 0.5 \text { mole } \% \mathrm{Fe}_{2} \mathrm{O}_{3}\end{aligned}$ & 1400/8/Air \\
\hline $13 N S-1500$ & & 1500/8/Air \\
\hline $13 \mathrm{NS}-1600$ & & 1600/8/Air \\
\hline 13 NS-12/88 & & $1600 / 1.5 /$ Gas bubbling $\left(\mathrm{CO} / \mathrm{CO}_{2}=12 / 88\right)$ \\
\hline $13 \mathrm{NS}-24 / 76$ & & $1600 / 1.5 /$ Gas bubbling $\left(\mathrm{CO} / \mathrm{CO}_{2}=24 / 76\right)$ \\
\hline 13NS-36/64 & & $1600 / 1.5 /$ Gas bubbling $\left(\mathrm{CO} / \mathrm{CO}_{2}=36 / 64\right)$ \\
\hline $13 \mathrm{NS}-50 / 50$ & & $1600 / 1.5 /$ Gas bubbling $\left(\mathrm{CO} / \mathrm{CO}_{2}=50 / 50\right)$ \\
\hline
\end{tabular}


Table II. Oxidation states of iron in glasses by the colorimetric method

\begin{tabular}{ccccc}
\hline Glass & $\mathrm{Fe}^{2+} / \Sigma \mathrm{Fe}(\%)$ & Error $(\%)$ & $\begin{array}{c}\text { Total Fe } \\
(\mathrm{g} \mathrm{Fe} / 100 \mathrm{~g} \text { Glass })\end{array}$ & $\begin{array}{c}\text { Batch Total Fe } \\
(\mathrm{g} \mathrm{Fe} / 100 \mathrm{~g} \text { Glass })\end{array}$ \\
\hline $18 \mathrm{NS}-1300$ & 6.22 & 3.5 & 0.866 & 0.92 \\
$18 \mathrm{NS}-1400$ & 9.55 & 2.9 & 0.845 & 0.92 \\
$18 \mathrm{NS}-1500$ & 14.37 & 3 & 0.850 & 0.92 \\
$18 \mathrm{NS}-1600$ & 17.33 & 1.3 & 0.850 & 0.92 \\
$18 \mathrm{NS}-12 / 88$ & 36.05 & 0.8 & 0.875 & 0.92 \\
$18 \mathrm{NS}-24 / 76$ & 51.54 & 1.2 & 0.889 & 0.92 \\
$18 \mathrm{NS}-36 / 64$ & 61.22 & 1 & 0.880 & 0.92 \\
$18 \mathrm{NS}-50 / 50$ & 90.78 & 0.4 & 0.992 & 0.92 \\
\hline $13 \mathrm{NS}-1400$ & 9.32 & 3.7 & 0.929 & 0.925 \\
$13 \mathrm{NS}-1500$ & 13.90 & 4 & 0.927 & 0.925 \\
$13 \mathrm{NS}-1600$ & 17.69 & 4 & 0.931 & 0.925 \\
$13 \mathrm{NS}-12 / 88$ & 52.62 & 1.4 & 0.939 & 0.925 \\
$13 \mathrm{NS}-24 / 76$ & 49.55 & 1.3 & 0.958 & 0.925 \\
$13 \mathrm{NS}-36 / 64$ & 60.09 & 1.2 & 0.943 & 0.925 \\
$13 \mathrm{NS}-50 / 50$ & 73.61 & 1.2 & 0.926 & 0.925 \\
\hline
\end{tabular}


Table III. Extinction coefficient of glasses calculated from Figures 2 and 3

\begin{tabular}{ccc|ccc}
\hline Glass & $\begin{array}{c}\text { Extinction coefficient } \\
\varepsilon\left(\mathrm{mm}^{-1}\right)\end{array}$ & $\begin{array}{c}\text { Mean } \varepsilon \\
\left(\mathrm{mm}^{-1}\right)\end{array}$ & Glass & $\begin{array}{c}\text { Extinction coefficient } \\
\varepsilon\left(\mathrm{mm}^{-1}\right)\end{array}$ & $\begin{array}{c}\text { Mean } \varepsilon \\
\left(\mathrm{mm}^{-1}\right)\end{array}$ \\
\hline $18 \mathrm{NS}-1300$ & 1.330 & 1.294 & $13 \mathrm{NS}-1400$ & 1.235 & 1.20 \\
$18 \mathrm{NS}-1400$ & 1.370 & & $13 \mathrm{NS}-1500$ & 1.211 & \\
$18 \mathrm{NS}-1500$ & 1.330 & & $13 \mathrm{NS}-1600$ & 1.257 & \\
$18 \mathrm{NS}-1600$ & 1.210 & & $13 \mathrm{NS}-12 / 88$ & 1.215 & \\
$18 \mathrm{NS}-12 / 88$ & 1.282 & & $13 \mathrm{NS}-50 / 50$ & 1.064 & \\
$18 \mathrm{NS}-24 / 76$ & 1.283 & & & & \\
$18 \mathrm{NS}-36 / 64$ & 1.260 & & & & \\
$18 \mathrm{NS}-50 / 50$ & 1.290 & & & & \\
\hline
\end{tabular}


Table IV. Oxidation states of iron in glasses by the spectrophotometric method

\begin{tabular}{cc|cc}
\hline Glass & $\begin{array}{c}\mathrm{Fe}^{2+} / \Sigma \mathrm{Fe}(\%) \\
(\text { Average } \varepsilon=1.294)\end{array}$ & Glass & $\begin{array}{c}\mathrm{Fe}^{2+} / \Sigma \mathrm{Fe}(\%) \\
(\text { Average } \varepsilon=1.20)\end{array}$ \\
\hline $18 \mathrm{NS}-1300$ & 5.76 & $13 \mathrm{NS}-1400$ & 9.74 \\
$18 \mathrm{NS}-1400$ & 9.42 & $13 \mathrm{NS}-1500$ & 15.24 \\
$18 \mathrm{NS}-1500$ & 13.90 & $13 \mathrm{NS}-1600$ & 18.82 \\
$18 \mathrm{NS}-1600$ & 22.58 & $13 \mathrm{NS}-12 / 88$ & 54.10 \\
$18 \mathrm{NS}-12 / 88$ & 34.02 & $13 \mathrm{NS}-50 / 50$ & 66.27 \\
$18 \mathrm{NS}-24 / 76$ & 49.38 & & \\
$18 \mathrm{NS}-36 / 64$ & 59.69 & & \\
$18 \mathrm{NS}-50 / 50$ & 88.76 & & \\
\hline
\end{tabular}


Table V. Comparison of slope ratios and concentration ratios of glasses

\begin{tabular}{cccc|cccc}
\hline Glass & Slope & $\begin{array}{c}\text { Slope Ratio } \\
\left(\mathrm{M} / \mathrm{M}_{1300}\right)\end{array}$ & $\begin{array}{c}\text { Concentration } \\
\text { Ratio } \\
\left(\mathrm{C} / \mathrm{C}_{1300}\right)\end{array}$ & Glass & Slope & $\begin{array}{c}\text { Slope Ratio } \\
\left(\mathrm{M}^{-} \mathrm{M}_{1400}\right)\end{array}$ & $\begin{array}{c}\text { Concentration } \\
\text { Ratio } \\
\left(\mathrm{C} / \mathrm{C}_{1400}\right)\end{array}$ \\
\hline $18 \mathrm{NS}-1300$ & 0.0831 & 1 & 1 & $13 \mathrm{NS}-1400$ & 0.1151 & 1 & 1 \\
$18 \mathrm{NS}-1400$ & 0.1308 & 1.57 & 1.54 & $13 \mathrm{NS}-1500$ & 0.1618 & 1.41 & 1.49 \\
$18 \mathrm{NS}-1500$ & 0.1919 & 2.31 & 2.31 & $13 \mathrm{NS}-1600$ & 0.2224 & 1.93 & 1.90 \\
$18 \mathrm{NS}-1600$ & 0.209 & 2.52 & 2.79 & $13 \mathrm{NS}-12 / 88$ & 0.6395 & 5.56 & 5.64 \\
$18 \mathrm{NS}-12 / 88$ & 0.462 & 5.56 & 5.80 & $13 \mathrm{NS}-50 / 50$ & 0.7833 & 6.81 & 7.90 \\
$18 \mathrm{NS}-24 / 76$ & 0.6614 & 7.96 & 8.29 & & & & \\
$18 \mathrm{NS}-36 / 64$ & 0.7736 & 9.31 & 9.84 & & & & \\
$18 \mathrm{NS}-50 / 50$ & 1.175 & 14.14 & 14.60 & & & & \\
\hline
\end{tabular}


Table VI. Molar extinction coefficient of ferrous iron in silicate glasses

\begin{tabular}{cccc}
\hline $\begin{array}{c}\text { Glass Composition } \\
(\text { Mole \%) }\end{array}$ & $\begin{array}{c}\text { Molar Extinction } \\
\text { Coefficient } \\
\left(l \text { mole }^{-1} \mathrm{~cm}^{-1}\right)\end{array}$ & $\begin{array}{c}\text { Peak } \\
\text { Wavelength } \\
(\mathrm{nm})\end{array}$ & Ref. \\
\hline $18.56 \mathrm{Na}_{2} \mathrm{O} \cdot 81.44 \mathrm{SiO}_{2}$ & 31.4 & 1140 & Present \\
$13 \mathrm{Na}_{2} \mathrm{O} \cdot 87 \mathrm{SiO}_{2}$ & 30.33 & 1170 & Present \\
$30 \mathrm{Na}_{2} \mathrm{O} \cdot 70 \mathrm{SiO}_{2}$ & 28.91 & 1050 & {$[12]$} \\
$30 \mathrm{Na}_{2} \mathrm{O} \cdot 70 \mathrm{SiO}_{2}$ & 27.9 & 1100 & {$[13]$} \\
$30 \mathrm{Na}_{2} \mathrm{O} \cdot 70 \mathrm{SiO}_{2}$ & 26.69 & 1100 & {$[14]$} \\
Commercial Soda- & 27.4 & 1100 & {$[15]$} \\
lime and Amber Glass & & & \\
\hline
\end{tabular}




\section{Table VII. Immiscibility temperatures of 18NS-series}

and 13NS-series glasses

\begin{tabular}{cc|cc}
\hline Glass & $\begin{array}{c}\text { Immiscibility } \\
\text { Temperature }\left({ }^{\circ} \mathrm{C}\right)\end{array}$ & Glass & $\begin{array}{c}\text { Immiscibility } \\
\text { Temperature }\left({ }^{\circ} \mathrm{C}\right)\end{array}$ \\
\hline $18 \mathrm{NS}$ & $660 \pm 2.5$ & $13 \mathrm{NS}$ & $767 \pm 2.5$ \\
$18 \mathrm{NS}-1300$ & $631 \pm 2.5$ & $13 \mathrm{NS}-1400$ & $735 \pm 2.5$ \\
$18 \mathrm{NS}-1400$ & $631 \pm 2.5$ & $13 \mathrm{NS}-1500$ & $737 \pm 2.5$ \\
$18 \mathrm{NS}-1500$ & $634 \pm 2.5$ & $13 \mathrm{NS}-1600$ & $739 \pm 2.5$ \\
$18 \mathrm{NS}-1600$ & $636 \pm 2.5$ & $13 \mathrm{NS}-12 / 88$ & $744 \pm 2.5$ \\
$18 \mathrm{NS}-12 / 88$ & $636 \pm 2.5$ & $13 \mathrm{NS}-24 / 76$ & $744 \pm 2.5$ \\
$18 \mathrm{NS}-24 / 76$ & $636 \pm 2.5$ & $13 \mathrm{NS}-36 / 64$ & $748 \pm 3.0$ \\
$18 \mathrm{NS}-36 / 64$ & $638 \pm 3.0$ & $13 \mathrm{NS}-50 / 50$ & $750 \pm 3.0$ \\
$18 \mathrm{NS}-50 / 50$ & $640 \pm 3.0$ & & \\
\hline
\end{tabular}




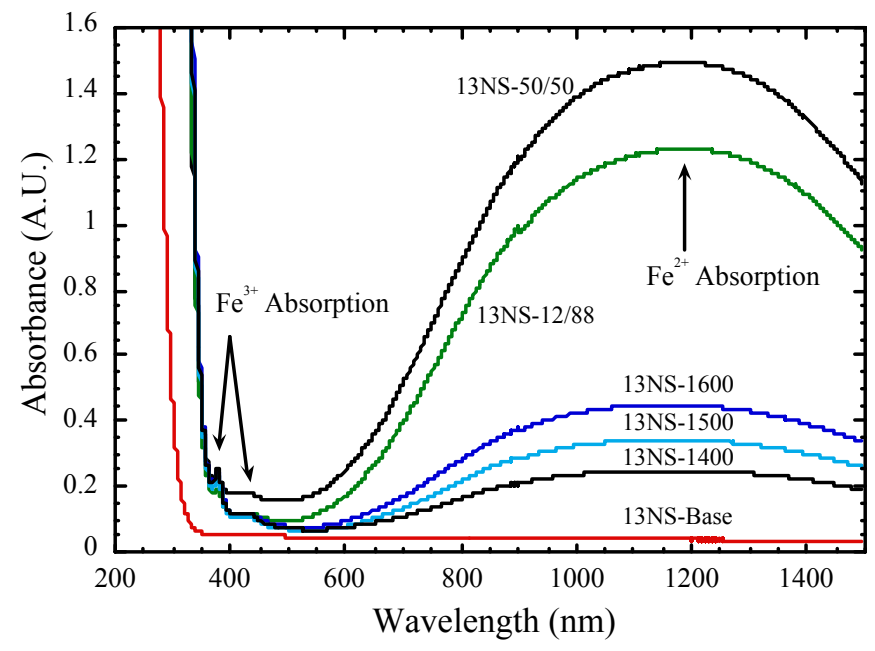

Figure 1. UV-VIS NIR spectra of 13NS-series glasses. 


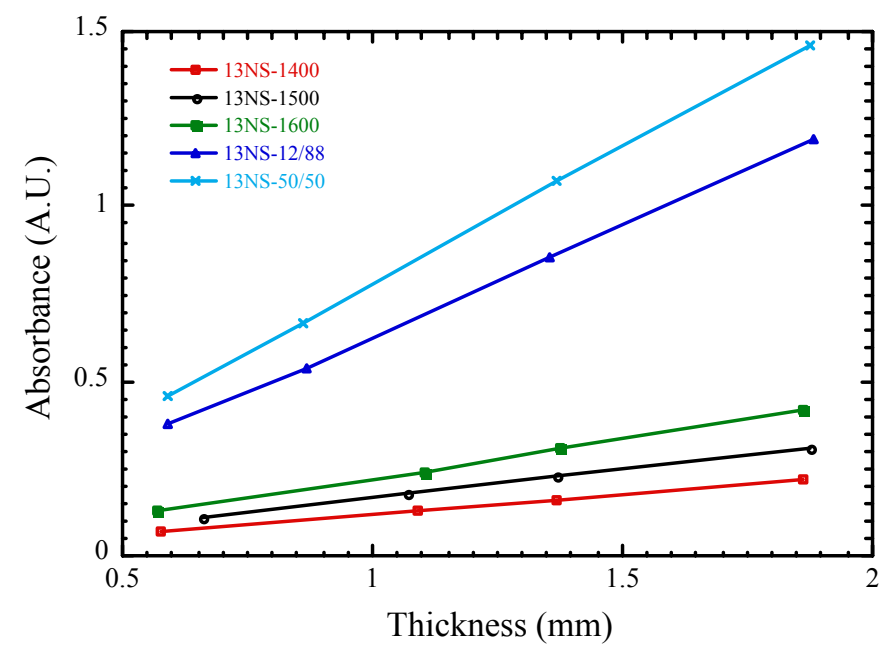

Figure 2. A plot of UV-VIS NIR absorbance versus thickness for 13NS-series glasses doped with 0.5 mole $\% \mathrm{Fe}_{2} \mathrm{O}_{3}$. 


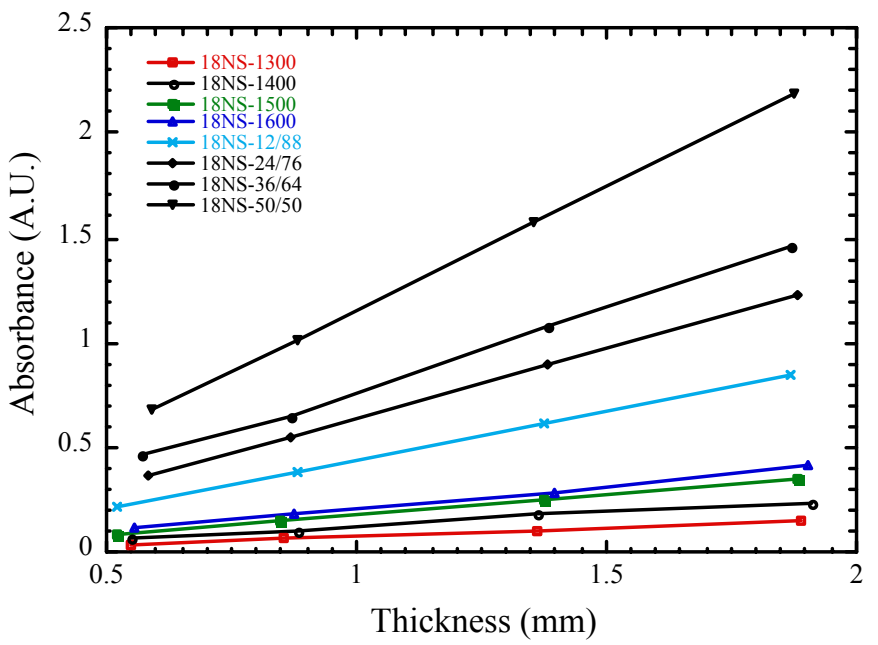

Figure 3. A plot of UV-VIS NIR absorbance versus thickness for 18NS-series glasses doped with 0.5 mole $\% \mathrm{Fe}_{2} \mathrm{O}_{3}$. 

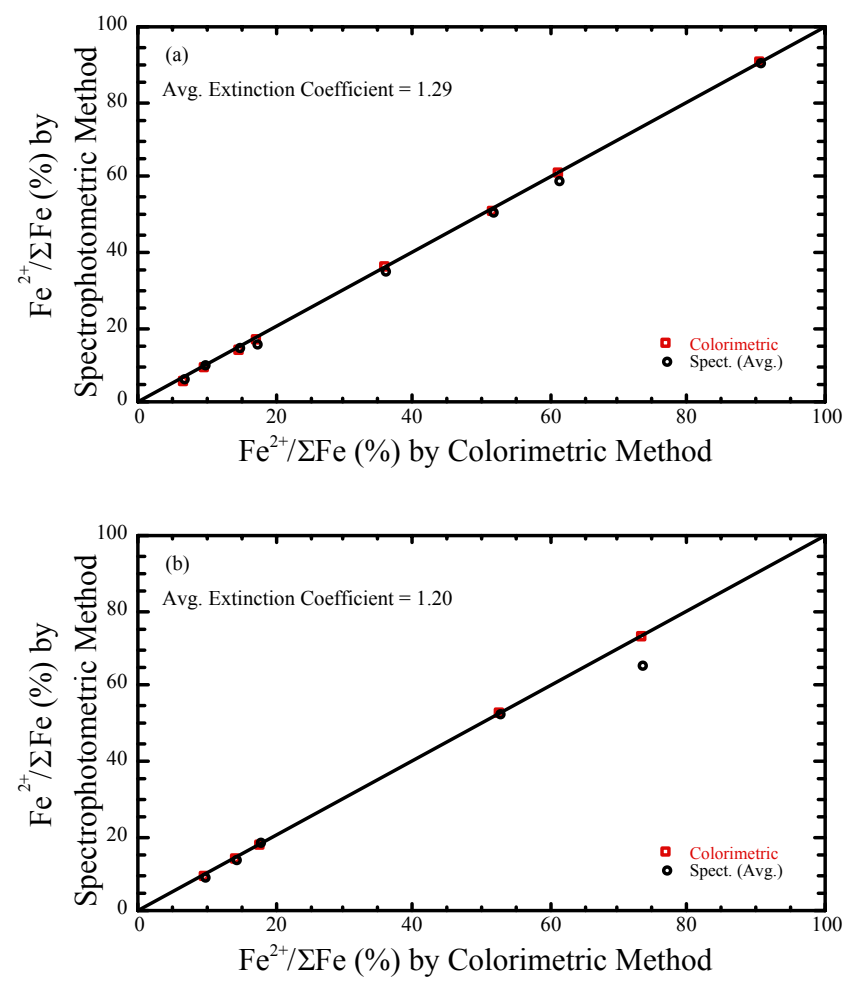

Figure 4. Comparison of the two different methods of iron oxidation state analysis: (a) for $18 \mathrm{NS}$-series and (b) for 13NS-series glasses. The solid line indicates a 1:1 correlation between the two techniques. 
(a)

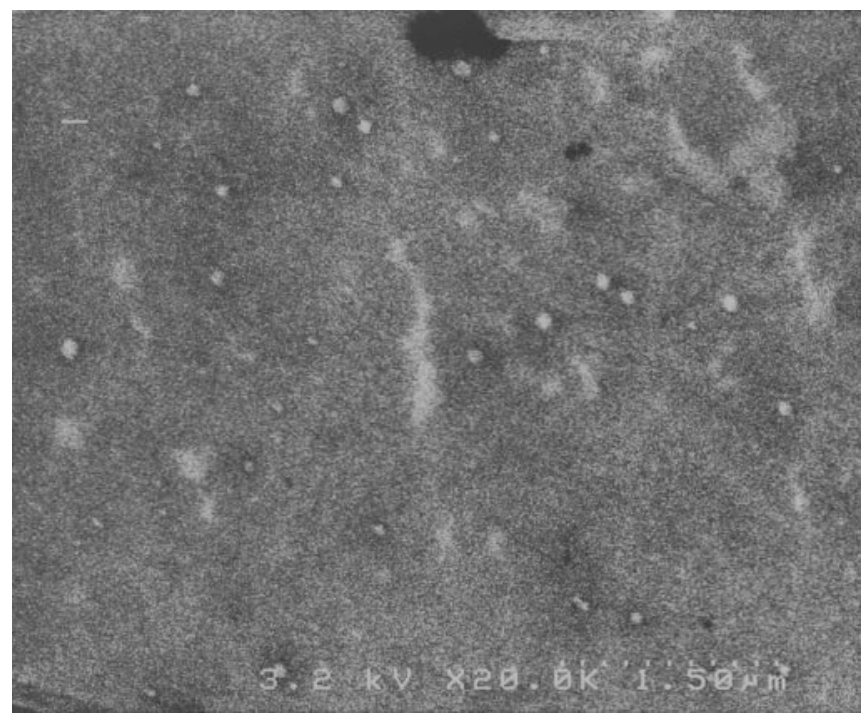

(b)

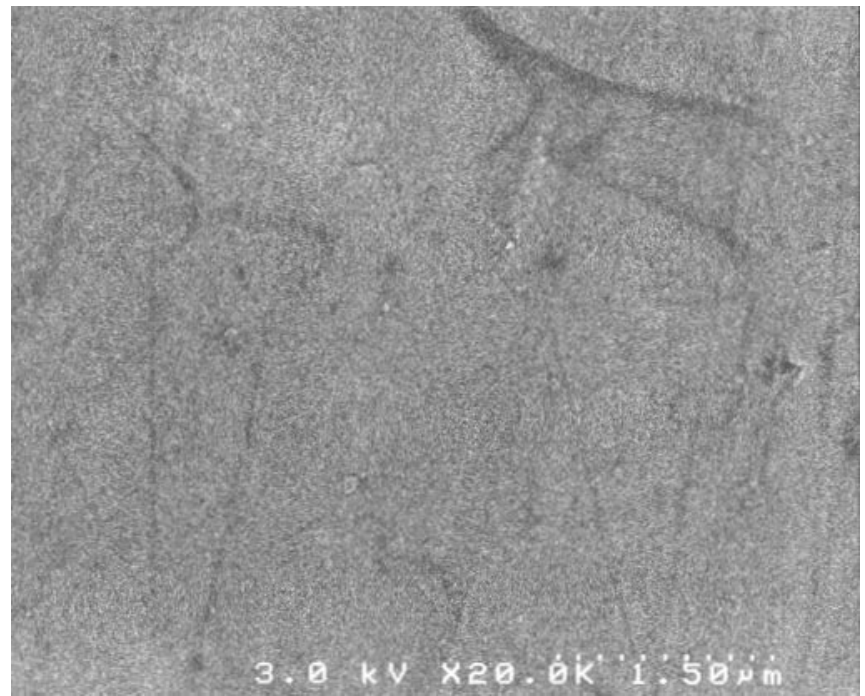

Figure 5 SEM micrographs of $18 \mathrm{NS}$ base glass heat treated at (a) $655{ }^{\circ} \mathrm{C}$ for $8 \mathrm{hrs}$, (b) $660{ }^{\circ} \mathrm{C}$, for $8 \mathrm{hrs}$. 


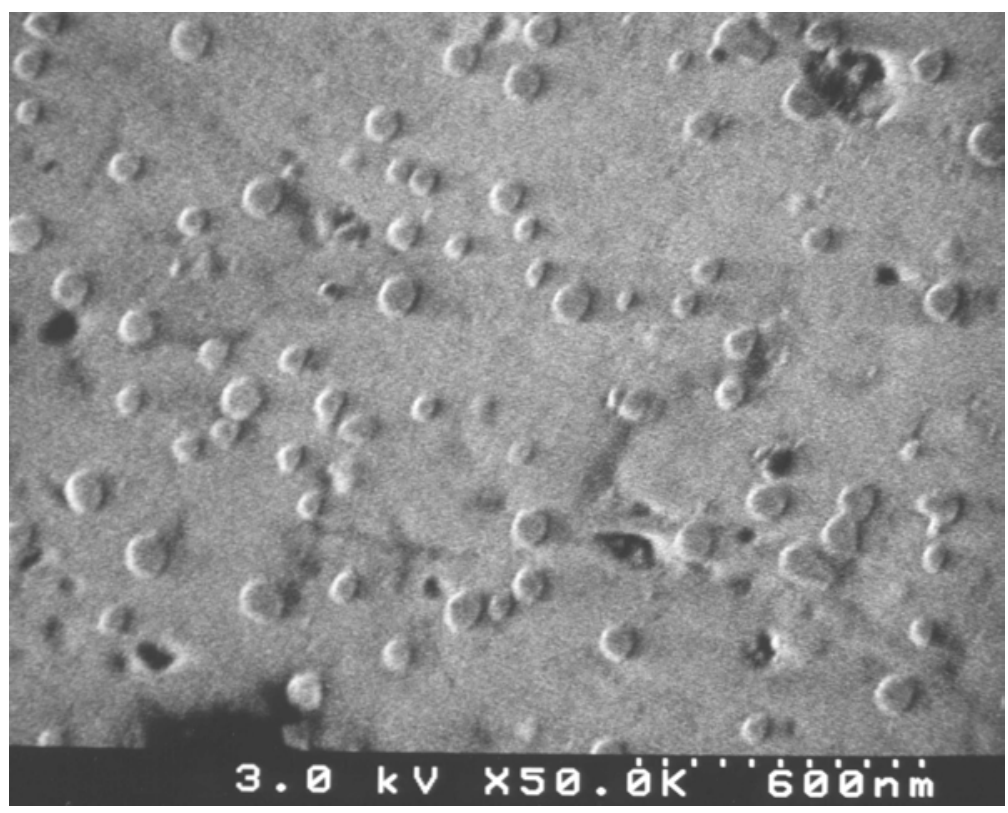

(a) $18 \mathrm{NS}-1300$ glass, heat treated at $596{ }^{\circ} \mathrm{C}$ for $8 \mathrm{hrs}$

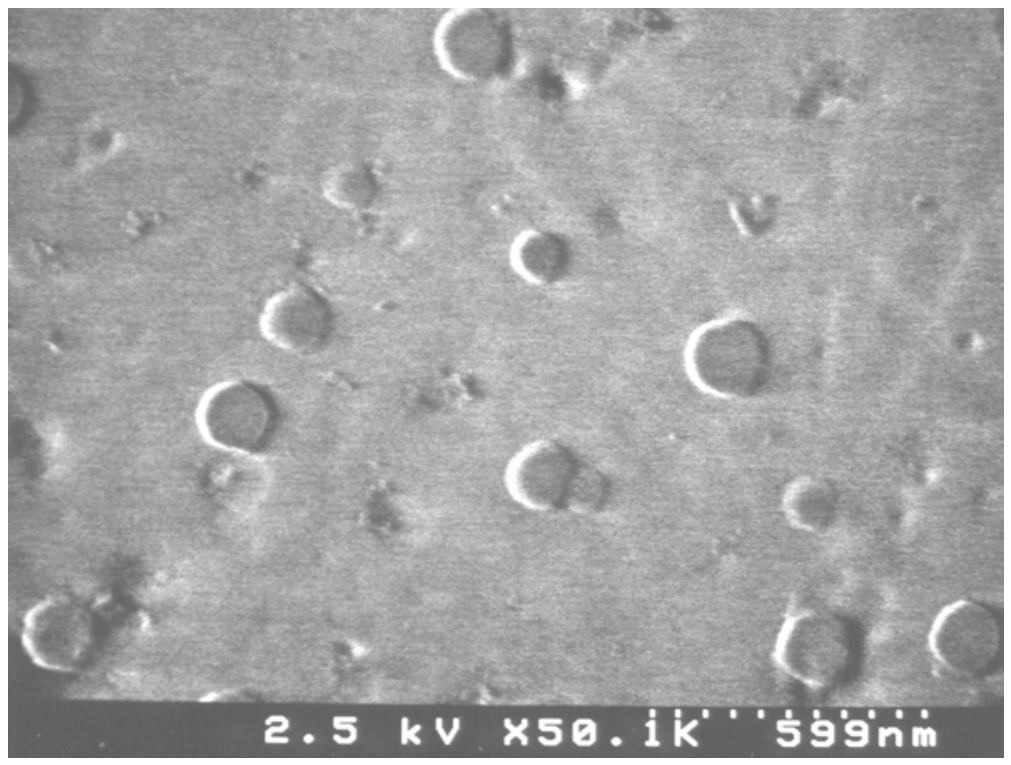

(b) $18 \mathrm{NS}-1400$ glass, heat treated at $598{ }^{\circ} \mathrm{C}$ for $8 \mathrm{hrs}$

Figure 6 FE-SEM micrographs of phase separated glasses 

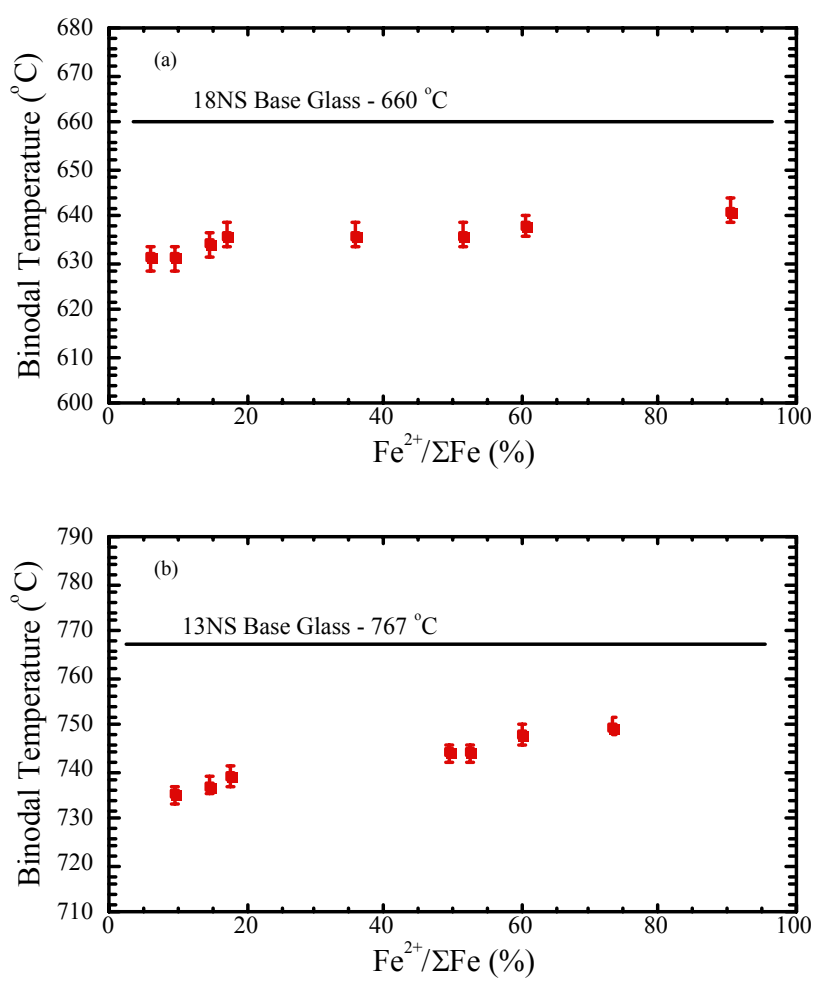

Figure 7. Effect of oxidation state of iron on the binodal temperature:

(a) $18.56 \mathrm{Na}_{2} \mathrm{O} \cdot 84.44 \mathrm{SiO}_{2}$ glasses doped with 0.5 mole $\% \mathrm{Fe}_{2} \mathrm{O}_{3}$.

(b) $13 \mathrm{Na}_{2} \mathrm{O} \cdot 87 \mathrm{SiO}_{2}$ glasses doped with 0.5 mole $\% \mathrm{Fe}_{2} \mathrm{O}_{3}$.

* The solid line is the binodal temperature of the base glass 
(a)
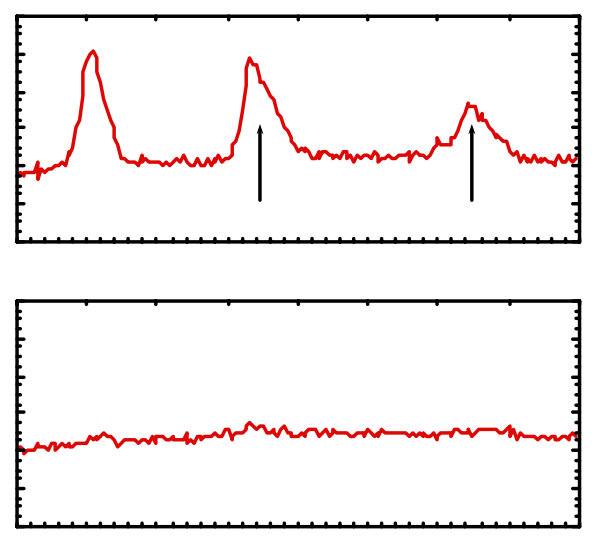

(b)
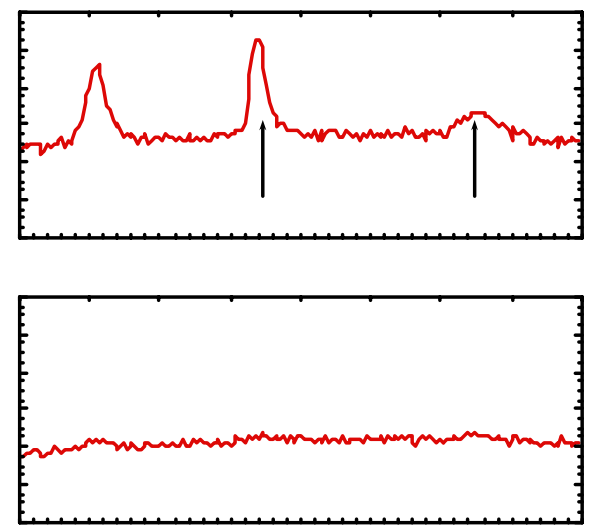

Figure 8. X-ray patterns of $18.56 \mathrm{Na}_{2} \mathrm{O} \cdot 81.44 \mathrm{SiO}_{2}$ heated glass: (a) base glass, and (b) glass doped with 0.5 mole $\% \mathrm{Fe}_{2} \mathrm{O}_{3}$. 


\section{PUBLICATIONS UNDER THIS GRANT}

The work summarized here resulted in a Master's Thesis being submitted by Mr. Jun-Sik Jeoung in the Department of Materials Science and Engineering at the University of Arizona, as well as a manuscript published in the Journal of the American Ceramic Society. The reference for the manuscript is given below:

J.S. Jeoung, W.H. Poisl, M.C. Weinberg, G.L. Smith, and H. Li, "Effect of Oxidation State of Iron on Phase Separation in Sodium Silicate Glasses", Journal of the American Ceramic Society, 84 [8] 1859-64 (2001). 